\title{
Interactive comment on "A High Speed Particle Phase Discriminator (PPD-HS) for the classification of airborne particles, as tested in a continuous flow diffusion chamber" by Fabian Mahrt et al.
}

\section{Anonymous Referee \#1}

Received and published: 28 February 2019

See attached pdf

Please also note the supplement to this comment: https://www.atmos-meas-tech-discuss.net/amt-2019-36/amt-2019-36-RC1supplement.pdf 